\title{
Drying Technology
}

An International Journal

\section{Comparison of Two Alternatives of Combined Drying to Process Blueberries ( $\left.\mathrm{O}^{\prime} \mathrm{Neal}\right)$ : Evaluation of the Final Quality}

\author{
A. Rodriguez, M. J. Zaro, M. L. Lemoine \& R. H. Mascheroni
}

To cite this article: A. Rodriguez, M. J. Zaro, M. L. Lemoine \& R. H. Mascheroni (2015):

Comparison of Two Alternatives of Combined Drying to Process Blueberries ( $O$ ' Neal):

Evaluation of the Final Quality, Drying Technology, DOI: 10.1080/07373937.2015.1089886

To link to this article: http://dx.doi.org/10.1080/07373937.2015.1089886

Accepted author version posted online: 29

Oct 2015.

Submit your article to this journal $\sqsubset$

Џll Article views: 6

Q View related articles $\llbracket$

View Crossmark data $\nearrow$ 


\title{
COMPARISON OF TWO ALTERNATIVES OF COMBINED DRYING TO PROCESS BLUEBERRIES (O'Neal): EVALUATION OF THE FINAL QUALITY.
}

\author{
A. Rodriguez ${ }^{1}$, M. J. Zaro ${ }^{1}$, M. L. Lemoine ${ }^{1,2}$, R. H. Mascheroni ${ }^{1,3}$ \\ ${ }^{1}$ CIDCA (Centro de Investigación y Desarrollo en Criotecnología de Alimentos), \\ CONICET- CCT La Plata-UNLP. Calles 47 y 116 s/n, CP 1900, La Plata, Argentina, \\ ${ }^{2}$ Laboratorio de Investigación en Productos Agroindustriales (LIPA), Fac. Cs. Agrarias y \\ Forestales-UNLP. Calle 60 y 119, CP 1900, La Plata, Argentina, ${ }^{3}$ Facultad de Ingeniería \\ UNLP, La Plata, Argentina \\ Corresponding autor to A. Rodriguez: 47 y 116, cp: 1900, La Plata, Buenos Aires. \\ Argentina. E-mail: anabelrodriguezracca@gmail.com
}

\begin{abstract}
In this work, we examined and compared two combined alternatives for the drying of blueberries ( $\mathbf{O}^{\prime}$ Neal). Pretreatments of osmotic dehydration $\left(60^{\circ}\right.$ Brix sucrose solution, at $40^{\circ} \mathrm{C}$ for $\left.6 \mathrm{~h}\right)$ and hot air drying $\left(60^{\circ} \mathrm{C}, 2.5 \mathrm{~m} / \mathrm{s}\right.$ for $\left.90 \mathrm{~min}\right)$ were performed to reach the same water content. Pretreated blueberries were then dried by microwave at different microwave output power values: $562.5 \mathrm{~W}, 622.5 \mathrm{~W}$ and $750 \mathrm{~W}$. The combined drying processes were also compared with hot air drying alone (control). The effects of the processes over blueberries were studied in terms of decrease in water content, drying rate, mechanical properties (firmness and stiffness), optical properties ( $\mathrm{L}^{*}, \mathrm{a}^{*}$ and hue angle (h)), antioxidant capacity and rehydration capacity. The hot air-microwave drying decreased the process time and presented a high drying rate compared with the osmotic dehydration-microwave processes and the control drying. In terms of quality, the antioxidant and rehydration capacities were the most affected. The results showed that the best drying method to obtain the desired final product was the hot air-microwave drying $(750 \mathrm{~W})$.
\end{abstract}


KEYWORDS: Blueberries, combined drying, texture, color, antioxidant capacity, rehydration capacity

\section{INTRODUCTION}

Blueberries (Vaccinium corymbosum cv. O'Neal), from the Southern highbush blueberries group, are one of the highly productive varieties commercially grown in Argentina. Blueberries are characterized by being rich in antioxidants, by having attractive sensorial attributes and by being increasingly requested by consumers, since they contribute to the nutritional quality of a diet [1]. However, the high perishability and limited shelf-life of blueberries is a common problem for their production. Processing methods such as dehydration are usually applied to extend their commercial life and even allow reducing storage and transportation costs [2,3]. More recently, researchers focus on improving drying techniques and also meeting consumer demand for high-quality dried commodities [4].

Value-added products based on blueberries could be designed by applying combined drying processes [5]. These processes include a mild pretreatment step such as osmotic dehydration, hot air drying at low temperature or solar drying, followed by microwave drying or another finishing drying method to reduce the disadvantages of using hot air drying alone and thus preserve the final product quality. The synergistic and additive effect of both drying stages allows preserving the food with a higher quality than when using only one method such as conventional drying [6]. 
Several authors have studied osmotic dehydration as a pretreatment and have found that it is a good alternative to preserve the attributes and nutritional value of fresh fruit $[2,57]$. Osmotic dehydration consists in the immersion of fruit in a hypertonic sugar solution. The sugar infusion allows removing a large amount of water and introducing sugar into fruits. However, a complementary method is required to produce a stable product. Microwave drying of osmotically dehydrated products has demonstrated to improve the drying rate and maintain product quality $[8,9]$.

Another alternative may be the combination of hot air drying and microwave drying. Hot air drying is the most common method used to dehydrate fruit. However, the main disadvantage of this process is that it takes a long time, even at high temperatures, which degrades the quality of the dried product [10]. On the other hand, microwave drying has been of great interest in the food industry because microwave waves may penetrate through untreated or partially dehydrated samples. This type of drying causes heating in the wet parts and increases the drying rate. Several authors have proposed that the combination of microwave drying and hot air drying may be used to overcome the disadvantages associated with the application of each method alone [10, 11, 12]. The application of hot air drying followed by microwave drying can reduce the costs and process time and obtain high-quality final products.

The aim of this work was to compare two combined drying processes, between them and with a control drying. We determined both the effect of the process variables 
over the efficiency of the drying time and the different quality parameters of blueberries (cv. $\mathrm{O}^{\prime} \mathrm{Neal}$ ) required to obtain a final product that can be used as a food ingredient.

\section{METHODS AND MATERIALS}

\subsection{Blueberries}

Blueberries (Vaccinium corymbosum cv. $\mathrm{O}^{\prime} \mathrm{Neal}$ ) were purchased from Don Pedro establishment in San Pedro (Buenos Aires, Argentina) and stored at $0^{\circ} \mathrm{C}$. Previous to the drying process, blueberries were washed and dried with tissue paper. The initial characteristics were: water content $83.44 \pm 1.01 \%$ (wb), soluble solids $13.5 \pm 0.8$ ( ${ }^{\circ} \mathrm{Brix}$ ) and initial water activity $0.978 \pm 0.001$.

\subsection{Chemical Pretreatment}

Previous to the drying process, blueberries were dipped on alkali emulsion of ethyl oleate (AEEO) for $1.5 \mathrm{~min}$ at $60^{\circ} \mathrm{C}$, to increase the permeability of the skin. The AEEO was prepared by mixing distilled water, ethyl oleate $(2 \% \mathrm{v} / \mathrm{v})$ and sodium hydroxide $(0.5 \% \mathrm{w} / \mathrm{v})$. The concentrations applied have been reported previously [13].

\subsection{Experimental Design Of The Drying Process}

Combined processes were performed in the following way: an initial stage where a portion of blueberries was pretreated with osmotic dehydration (OD) and another portion with hot air drying (HAD), and a second stage in which all pretreated blueberries were exposed to microwave drying (MWD). All the drying processes were performed in 
triplicate. The conditions of the pretreatments OD and HAD were selected by preliminary tests [14].

OD was performed in a solution of commercial sucrose of $60^{\circ}$ Brix at $40^{\circ} \mathrm{C}$ for 360 min with constant agitation $(100 \mathrm{rpm})$ in a shaker (brand Ferca, Argentina). The fruit/syrup relation selected was 1:20 and the sample amount used was $90 \pm 0.5 \mathrm{~g}$.

HAD was performed in a horizontal prototype drier (Didacta Italia) adapted in our Institute, supplied with stainless steel trays. The conditions were air temperature at $60^{\circ} \mathrm{C}$ and air speed $2.5 \mathrm{~m} / \mathrm{s}$ for $90 \mathrm{~min}$. This pretreatment time allowed reaching the same water content as that of OD, to compare both combined drying methods. The control drying was performed in the same conditions but for $480 \mathrm{~min}$. The sample amount used was $60 \pm 0.5 \mathrm{~g}$

MWD was performed with a domestic microwave oven (brand Whirlpool, model JT 359, China) with the incorporation of an autotransformer (E1 Toroide, Argentina), which allowed working with the magnetron set at the highest power $(750 \mathrm{~W})$ in a continuous way (without the on/off cycles of the normal control) and at different discrete levels of power $(100 \%, 83 \%$ and $75 \%$ of the set power). In this way, the operation conditions simulated the performance of continuous industrial equipment. Each percentage set in the autotransformer was imposed to the microwave oven working at its maximal power to obtain: $750 \mathrm{~W}(100 \%), 622.5 \mathrm{~W}(83 \%)$ and $562.5 \mathrm{~W}(75 \%)$. The sample amount for each experiment was $24.5 \pm 0.5 \mathrm{~g}$. 
Blueberries were dried until reaching a water activity value $<0.6$. In this way, dried blueberries were considered stable against the microbiological agents and chemical reactions. On the other hand, all processes were performed within a total operation time similar to that of a workday in the food industry (8h).

\subsection{Determination Of Water Content And Water Activity}

Water content $(W C)$ was determined by drying the blueberries in an oven

(Gallenkamp, UK) at $70^{\circ} \mathrm{C}$ until constant weight (24h), according to the AOAC method with some modifications [15]. Water content was calculated using equation (1):

$$
\mathrm{WC}=\frac{\mathrm{m}_{\mathrm{w}}}{\mathrm{m}_{\mathrm{t}}} * 100
$$

Where $\mathrm{WC}$ is the water content $(\%-\mathrm{wb}-), \mathrm{m}_{\mathrm{t}}$ is total mass $(\mathrm{g})$, and $\mathrm{m}_{\mathrm{w}}$ is water mass $(\mathrm{g})$. All measurements were performed in duplicate.

Water activity (aw) was determined at $25^{\circ} \mathrm{C}$ by the $\mathrm{AOAC}$ hygrometric method 978.18 [15], using a temperature-controlled AquaLab 3TE meter (Decagon Devices, Inc.). All measurements were performed in duplicate [16].

\subsection{Drying Rate}

The moisture ratio (MR) of samples was calculated using equation (2):

$$
\mathrm{MR}=\frac{\mathrm{Mt}-\mathrm{Me}}{\mathrm{Mo}-\mathrm{Me}} \cong \frac{\mathrm{Mt}}{\mathrm{Mo}}
$$

where $\mathrm{Mt}$ is the moisture content at any time ( $\mathrm{kg}$ water/ $\mathrm{kg}$ dry solid), Mo is the initial moisture content ( $\mathrm{kg}$ water/ $\mathrm{kg}$ dry solid), and Me is the equilibrium moisture content of 
the sample ( $\mathrm{kg}$ water $/ \mathrm{kg}$ dry solid). This equation can be simplified because the values of Me are relatively small, hence the error involved in the simplification is negligible [17, $18]$.

The drying rate (DR) was calculated as the derivative of MR over time, considering that MR has an exponential decay with time:

$$
\begin{aligned}
& M R=a^{*} e^{\left(-k^{*} t\right)} \\
& D R=\frac{d M R}{d t}=-k^{*} a * e^{\left(-k^{*} t\right)}
\end{aligned}
$$

$\mathrm{DR}\left(\mathrm{min}^{-1}\right)$ is the drying rate, MR is the moisture ratio, $\mathrm{t}$ is time (min), and $a$ and $k$ are constants. A graph of DR vs. MR was used to determine the drying behavior.

\subsection{Analysis Of Mechanical Properties}

The mechanical properties of the natural fresh and dried blueberries were evaluated using a puncture test. Measurements were performed at $25^{\circ} \mathrm{C}$ in a Texture Analyzer (model TA-XT2, Stable Microsystems, England) at a constant speed of $0.5 \mathrm{~mm} / \mathrm{s}$ using a cylindrical puncture probe of $3 \mathrm{~mm}$ in diameter. All determinations were performed in 15 replicates. The parameters analyzed were: Firmness $(\mathrm{N})$, i.e. the maximum force to break the sample, and Stiffness ( $\mathrm{N} / \mathrm{mm})$, i.e. the slope of the force-distance curve from the origin of the curve to the breaking point [19].

\subsection{Analysis Of The Optical Properties}

The optical properties of the natural fresh and dried blueberries were determined using a colorimeter Konica Minolta Chromameter (Model CR 400/410, Japan). The instrument was calibrated with a standard white reflector plate and the system selected was CIE L* 
$a^{*} b^{*}$. This system has been suggested by other authors [20] as the best color space for quantification in food with curved surfaces.

All determinations were carried out in 15 replicates. The results were expressed as L*, a* and hue angle (h). The $h$ was calculated using equation (5):

$$
\mathrm{h}=\operatorname{arctang}\left(\frac{\mathrm{b} *}{\mathrm{a} *}\right)
$$

\subsection{Analysis Of The Antioxidant Capacity}

\subsubsection{Reagents And Standards}

ABTS2, 2'-azino-bis (3-ethylbenzothiazoline-6-sulphonic acid), Trolox (6-hydroxy-2, 5, 7, 8-tetramethylchroman-2-carboxylic acid), potassium persulphate and DPPH $(2,2-$ diphenyl-1-picry-hydrazyl) were purchased from Sigma-Aldrich Corporation, Buenos Aires, Argentina.

\subsubsection{Determination With The DPPH Method}

The DPPH radical scavenging activity test of blueberries was performed according to the method described by Shimada et al. [21] with some modifications. Measurements were performed with $1 \mathrm{~mL}$ of DPPH solution $(0.05 \mathrm{~g} / \mathrm{L}$ in $96 \%$ ethanol) added to $0.5 \mathrm{~mL}$ of ethanol extracts of blueberries in concentrations of $0.5,1,1.5$ and $2 \mathrm{mg} / \mathrm{mL}$ and reacted at room temperature for $60 \mathrm{~min}$. The absorbance was measured at $515 \mathrm{~nm}$ with a Hitachi spectrophotometer model U-1900 (England). The sample mass required to cause 50\% DPPH inhibition $\left(\mathrm{EC}_{50}\right)$ was determined. All determinations were performed in duplicate. 


\subsubsection{Determination With The ABTS Method}

ABTS radical cation scavenging activity was determined according to the method described by Re et al. [22]. $\mathrm{ABTS}^{+}$was produced by mixing ABTS stock solution $(7 \mathrm{mM})$ with potassium persulfate $(2.45 \mathrm{mM})$. The solution was held at room temperature in darkness for $960 \mathrm{~min}$. Once the radical was formed, the absorbance was adjusted to 0.7 at $734 \mathrm{~nm}$ by dilution with $96 \%$ ethanol. $\mathrm{ABTS}^{+}$solution was prepared for each analysis. $\operatorname{ABTS}^{+}(1 \mathrm{~mL})$ was added to $20 \mu \mathrm{L}$ of ethanol extracts of blueberries and the reaction mixture was allowed to stand at $25^{\circ} \mathrm{C}$ for 6 min and the absorbance at $734 \mathrm{~nm}$ was immediately recorded. The measure becomes valid when $20-80 \%$ of inhibition is obtained, compared to the absorbance of a blank solution prepared with $20 \mu \mathrm{L}$ of $96 \%$ ethanol and $1000 \mu \mathrm{L}$ of $\mathrm{ABTS}^{+}$(without extract). The standard curve was performed using Trolox, with well-known concentrations. All determinations were performed in duplicate.

The results are expressed as the percentage of antioxidant retention and were calculated using the following equation (6):

$$
\text { AntioxidantRetention }(\%)=100-\left(\frac{A C o-A C t}{A C o} * 100\right)
$$

where $\mathrm{ACo}$ is the initial antioxidant capacity and $\mathrm{ACt}$ is the antioxidant capacity at the end of the drying process.

\subsection{Analysis Of The Rehydration Capacity}

Dried blueberries were rehydrated by immersion in distilled water in a 1:10 ratio for 120 min. The rehydration time was selected based on that reported by other authors [7, 23]. 
The rehydration capacity can be expressed as the weight ratio between the rehydrated sample and the sample before rehydration (g) [24]. The rehydration capacity was calculated using the following equation (7):

$$
\mathrm{RC}=\frac{\mathrm{m}_{\mathrm{r}}}{\mathrm{m}_{\mathrm{s}}}
$$

where $\mathrm{RC}$ is the rehydration capacity, $\mathrm{m}_{\mathrm{s}}$ is the dried mass $(\mathrm{g})$ and $\mathrm{m}_{\mathrm{r}}$ is the rehydrated mass (g). The mechanical properties of the rehydrated blueberries were analyzed as described in section 2.6.

\subsection{Statistical Analysis}

The statistical analysis was performed using SYSTAT software version 12. Results are presented as the average of three determinations $\pm \mathrm{SD}$ (standard deviation). The results obtained were analyzed using one-way analysis of variance (ANOVA). The process variables and their interactions that presented a $p<0.05$ indicated significant effects over fruit. The means were compared through a Tukey analysis at $95 \%$ level of trust. Significant differences were found when $\mathrm{p}<0.05$.

\section{RESULTS AND DISCUSSION}

\subsection{Comparison Of The Combined Dryings Of Blueberries}

Moisture-time diagrams showed different behaviors depending on the conditions applied (Figure 1a). The control drying was performed with HAD because MWD -as the only drying- generated a lower yield of undamaged blueberries (data not shown). Although blueberries were pretreated with AEEO to eliminate the wax of skin, the skin was not very porous. When the MW energy is converted into thermal energy within moist 
materials, the vapor pressure increases [25]. The skin hinders the exit of the vapor inside the blueberries, leading to the rupture of the fruit structure. On the other hand, OD was not applied as control drying due to it slow efficiency compared to the hot-air drying. This behavior can be seen in Figure 1a, which shows that OD requires more process time to decrease the water content to a determined value.

Regarding the combined processes, neither OD nor HAD decreased the water content in great proportion (only 4\%), but allowed keeping intact the superficial structure of the fruit during MWD. The cell membrane of blueberries experienced physicochemical changes that made it more flexible, a fact that facilitated the diffusion of the water vapor. The HAD pretreatment (90 min) was 75\% more efficient in process time than OD (360 min) to reach the same water content (Figure 1a). On the other hand, the HAD-MWD processes had a lower process time (66-73\%) than the control drying (Figure 1a). Similar results were obtained by Zielinska et al. [26] in the combined drying of blueberries. These authors observed that the use of microwaves throughout the entire drying process or in the final stage of the hot air-microwave drying could shorten the drying process by up to $95 \%$ in comparison with hot air drying. The OD-MWD processes and the control drying had similar process times because of the time required in the OD stage (Figure 1a).

The increase in the microwave power allowed decreasing the process time (Figure $1 \mathrm{~b}$ and 1c). By working at $750 \mathrm{~W}$ instead of at $562.5 \mathrm{~W}$, the process time of OD-MWD decreased between 9 and 11\%, whereas the process time of HAD-MWD decreased between 12 and 
$18 \%$. Similar results were reported by Venkatachalapathy and Kamadenahally [27] in the combined drying of blueberries and Stanislawski [28] in the combined drying of sliced carrots.

When the microwave output power of $562.5 \mathrm{~W}$ was applied, blueberries pretreated with OD took more time to reach the stable condition $(a w \leq 0.6)$ than the blueberries pretreated with HAD (Figure $1 \mathrm{~b}$ and $\mathrm{c}$ ). This behavior might be justified probably because OD favors sugar crystallization in some parts of the outer layers of blueberry tissues, hindering water transfer [29].

When analyzing the kinetics of the variation in water activity (Figure 2), we found that this parameter was unaffected during the pretreatments but quickly decreased when the microwave process was applied. All dried samples reached an aw value in the range of 0.45 to 0.55 .

\subsection{Drying Rate}

The drying rate (DR) demonstrated that the water removal from blueberries depended on the drying method (Figure 3). These results are consistent with those of Therdthai and Zhou [30] in the drying of mint leaves and with those of de Bruijn and Bórquez [31] in the combined drying of strawberries.

At the beginning of MW drying, the DR was higher due to the higher moisture content in the blueberries. As the drying advanced, the moisture gradient within the product 
decreased, hindering the transport of the moisture, and the DR decreased (Figure 3). Alibas [32] observed that as the drying progressed, the loss of moisture in the product caused a decrease in the absorption of microwave power and resulted in a fall in the drying rate. These results suggest that diffusion was the dominant physical mechanism of moisture movement [29].

The DR of the control drying was lower than that of the MWD. Also, the DR increased with the increase in the microwave output power (Figure 3), in agreement with that reported by other authors $[10,32]$. This behavior is due to the internal heating generated by MW. The evaporation that occurs inside blueberries creates additional partial pressure and concentration gradients of water vapor [8], which act as additional driving forces to enhance the mass flux of water and thus the effective water diffusion rate during MWD [31].

The combined processes were able to reduce the moisture content of blueberries.

However, when OD was applied as pretreatment, this combination resulted in a lower DR in the MW stage than that of samples with HAD pretreatment. This could be attributed to the fact that OD decreases the dielectric constant and yields a reduced absorption of microwave energy by the product [33].

\subsection{Mechanical Properties}

The mechanical puncture tests applied to dried blueberries showed that both firmness and stiffness were significantly affected by the conditions of the treatments (Figure $4 a$ and $b$ ). 
The control drying promoted both firmness and stiffness. This mechanical behavior is probably due to the lower porosity and the formation of a surface crust as a consequence of the long time required to reach the stable condition $(\mathrm{aw}<0.6)$ in the blueberries [34]. Cui et al. [35] reported that the shrinkage and collapse took place during the whole hotair drying, resulting in low transport rate of water and prolonged drying time and increased tough texture.

Regarding the combined processes, the increase in the microwave power decreased the firmness and stiffness of the dried blueberries, independently of the pretreatments. Blueberries dried at $622.5 \mathrm{~W}$ and $750 \mathrm{~W}$ had a softer and less firm texture than those of the control drying, whereas blueberries dried at $562.5 \mathrm{~W}$ had slightly lower mechanical responses than those of the control drying (Figure 4a and b). This is common in MWD due to the fast water evaporation, which yields a more open structure and lower shrinkage degree as a result of the vapor expansion within the product [31]. These characteristics may indicate that dried blueberries reached a rubbery state [34]. It is believed that if the texture of the dried blueberries is softer, the quality is better [36].

\subsection{Optical Properties}

The desired color properties for dried blueberries were values of $\mathrm{L}^{*}, h$ and $\mathrm{a}^{*}$ near 36 , $300^{\circ}$ and 0.272 , respectively. These values represent a blue-purple coloration on the surface of the fruit.

Before drying, blueberries were dipped into AEEO, which led to an increase in $h$ and a* 
(Figure 5a and b). Blueberries treated with AEEO presented a more purple-reddish coloration than natural fresh blueberries (Figure 5a and b). This color change may be due to the addition of $\mathrm{NaOH}$, which generates a $\mathrm{pH}$ change that controls the enzyme activities, involving pigment destruction, as reported for browning reactions $[37,38]$. Regarding lightness, it presented no significant differences (Figure 5c). This may be due to the dark coloration of blueberries where the light beam emitted by the colorimeter might be reflected in the same way for fresh and treated fruits. Münsell [39] and Moreno and Victor [40] reported that two different colors (as red and blue) can reach same lightness values if we consider the concept as the same degree of clarity and darkness in relation to the same amount of white and black content.

When comparing the different combined processes and the control drying, the ANOVA showed that $h$ and $\mathrm{a}^{*}$ presented significant differences $(\mathrm{p}<0.05)$ between the drying methods (Figure 5a and b). Blueberries pretreated with OD presented a purple-reddish tonality (Figure $5 \mathrm{a}$ and $\mathrm{b}$ ). These results suggest that OD had a protective effect on the color of the dried blueberries in the final process $[41,42]$. However, the samples treated with OD-MWD maintained the color obtained at the end of the chemical pretreatment (undesired color property).

On the other hand, blueberries dried with HAD-MWD and control drying presented hand $\mathrm{a}^{*}$ values near $300^{\circ}$ and $0.3-0.4$, respectively (bluer coloration). Similar results were obtained by Yemmireddy [3] in blueberries dried by forced air drying. This behavior may be due to the conversion of the reddish anthocyanins to colorless carbinol base and to the 
fact that the remaining bluish brown copigments started to dominate the color of dried blueberries [43].

The lightness of blueberries was not significantly affected $(\mathrm{p}>0.05)$ by the drying conditions (Figure 5c). The difference in lightness between the natural fresh blueberries, the blueberries treated with AEEO and the blueberries treated with the different drying methods was very low, indicating that the dried blueberries retained their typical dark color after drying [3]. Besides, through a visual evaluation, we observed that the surface color of the dried blueberries subjected to the different drying methods had no important changes.

\subsection{Antioxidant Capacity}

As described in the Materials and Methods section, the effect of the different drying treatments on the antioxidant characteristics of blueberries was evaluated by the ABTS and DPPH assays. The results were expressed in terms of percentage of retention of the antioxidant capacity (AC) respect to fresh fruit. Results showed a similar pattern for both assays. All the samples processed presented a significant decrease in AC. The highest antioxidant retention was observed in blueberries dried by the control drying (HAD), reaching 46 and $76 \%$ retention for $\mathrm{ABTS}$ and $\mathrm{DPPH}$, respectively, whereas the lowest antioxidant retention was observed in blueberries dried by the combined treatments ODMWD $622.5 \mathrm{~W}$ and 562.5W (Figure 6a and b). Although the control drying was a long process, the temperature was always $60^{\circ} \mathrm{C}$, which preserved the antioxidant capacity of dried blueberries [44]. Garau et al. [45] reported that the most appropriate drying 
temperature to preserve the $\mathrm{AC}$ of products would be around $60^{\circ} \mathrm{C}$, which suggests that antioxidant compounds have a higher resistance to heat degradation at this temperature.

In contrast, the combined processes allowed reaching the stable condition $(\mathrm{aw}<0.6)$ in less time than the control drying, but the nutraceutical properties of blueberries were significantly affected $(\mathrm{p}<0.05)$. This is because the temperature inside the fruit may increase above the boiling temperature of water, which generates overheating, with the consequent degradation of the antioxidant compounds [25]. The highest antioxidant retention was observed in blueberries treated by HAD-MWD-750W. This phenomenon was due to the fact that dried blueberries were less time exposed under these conditions, which generated less degradation of the antioxidant compounds. Similar trends were found by Ghanema et al. [46], who reported that antioxidant compounds were less affected with the increase in the microwave power.

\subsection{Rehydration Capacity}

The rehydration capacity of dried blueberries was significantly affected by the process conditions (Figure 7a). Dried blueberries presented low rehydration capacity (21\%-56\%), reaching a water content of 35-37\% (-wb-). Similar results were obtained by Nsonzi and Ramaswamy [43] on the rehydration ratios of rabbiteye blueberries dried using osmoconvective dried blueberries or conventionally air-dried (control) blueberries. This behavior may be due to the fact that the skin of blueberries presents high resistance to moisture diffusion [25]. On the other hand, distortion of cells and capillaries in plant 
tissue due to the thermal process may lead to textural changes, thus lowering the water absorption characteristics and affecting the rehydration capacity [47].

Microwave drying allowed a higher rehydration of blueberries (20\% more) than the control drying, which means that this method generates less thermal damage on the blueberries structure. Similar results were obtained by Drouzas and Schubert [48], who reported that the lower rehydration values evidence the product shrinkage caused by severe heating and/or prolonged drying, which generates irreversible physicochemical changes. These changes seemed to be lower in the microwave finish dried blueberries.

\begin{abstract}
All rehydrated blueberries presented much lower firmness and stiffness than natural fresh blueberries (Figure $7 \mathrm{~b}$ and $\mathrm{c}$ ). These results suggest that the loss of tissue integrity and the collapse of the structure of dried blueberries decrease the hydrophilic properties, generating modifications in the firmness and stiffness associated with the thermal damage of the fruit $[49,50]$.
\end{abstract}

The rehydrated blueberries obtained with the control drying presented higher firmness and stiffness than those obtained with the combined drying processes. On the other hand, blueberries dried by HAD-MWD and OD-MWD presented different firmness and stiffness. These results showed that blueberries pretreated with OD were slightly less firm and stiff than those pretreated with HAD. This behavior may be explained by the fact that the sugar uptake during OD minimized shrinkage, thus reducing the compactness of the dried samples [51]. 
The analysis of the rehydration capacity allowed defining the properties of dried blueberries as products. All samples presented low rehydration capacity but softer texture than natural fresh blueberries. Thus, this product may be used as a food ingredient where high rehydration is not needed, like in cereal bars or ice creams [52].

\section{CONCLUSIONS}

The determinations of different parameters of quality allowed selecting the best conditions of blueberry drying. All the drying processes reached the stable condition in dried blueberries $(\mathrm{aw}<0.6)$ within 8 hours of process, being feasible for the food industry. On the other hand, the final product showed good quality characteristics which may be used as food ingredient in products that do not need high rehydration, like cereal bars or ice cream. Based on the results of the drying rate, optical properties, mechanical properties, the retention of antioxidant capacity and rehydration capacity, we conclude that the best drying process to obtain the desired final product was the hot air-microwave drying (750W).

\section{ACKNOWLEDGMENTS}

We thank the cooperation from the Universidad Nacional de La Plata (UNLP) and Consejo Nacional de Investigaciones Científicas y Técnicas (CONICET), Argentina.

\section{REFERENCES}

1. Kalt, W., Ryan, D.A., Duy, J.C., Prior, R.L., Ehlenfeldt, M.K. and Vander Kloet, S.P. Interspecific variation in anthocyanins, phenolic, and antioxidant capacity among 
genotypes of Highbush and Lowbush blueberries (Vaccinium section cyanococcus spp.).

Journal of Agricultural and Food Chemistry 2001, 49(10), 4761-4767.

2. Stojanovic, J. and Silva, J.L. Influence of osmotic concentration, continuous high frequency ultrasound and dehydration on antioxidants, color and chemical properties of rabbiteye blueberries. Food Chemistry 2007, 101, 898-906.

3. Yemmireddy, V.K., Chinnan, M.S., Kerr, W.L., Hung, Y. Effect of drying method on drying time and physic-chemical properties of dried Rabbiteye blueberries. LWT Food Science and Technology 2013, 50(2), 739-745.

4. Mothibe, K.J., Wang, C.Y., Mujumdar, A.S., Zhang, M. Microwave-assisted pulse-spouted vacuum drying of apple cubes. Drying Technology 2014, 32(15), 1762 1768.

5. Giovanelli, G., Brambilla, A., Rizzolo, A. and Sinelli, N. Effects of blanching pretreatment and sugar composition of the osmotic solution on physic-chemical, morphological and antioxidant characteristics of osmodehydrated blueberries (Vaccinium corymbosum L.). Food Research International 2012, 49(1), 263-271.

6. Genina, P. Deshidratación osmótica: alternativa para conservación de frutas tropicales. Avance y Perspectiva 2002, 21, 321-324. Retrieved from http://scholar.google.com/scholar?hl=en\&btnG=Search\&q=intitle:Deshidratación+osmóti ca+: +alternativa + para + conservación + de + frutas + tropicales $\# 0$.

7. Ramaswamy, H.S. and Nsonzi, F. Convective-air drying kinetics of osmotically pretreated blueberries. Drying Technology 1998, 16(3-5), 743-759.

8. Contreras, C., Martín-Esparza, M.E., Chiralt, A., Martínez-Navarrete, N. Influence of microwave application on convective drying: Effects on drying kinetics, and optical 
and mechanical properties of apple and strawberry. Journal of Food Engineering 2008, $88,55-64$.

9. Heredia, A., Peinado, I., Rosa, E. and Andrés, A. Effect of osmotic pre-treatment and microwave heating on lycopene degradation and isomerization in cherry tomato. Food Chemistry 2010, 123, 92-98.

10. Sharma, G.P. and Prasad, S. Drying of garlic (Allium sativum) cloves by microwavehot air combination. Journal of Food Engineering 2001, 50, 99-105.

11. Maskan, M. Kinetics of color change of kiwifruits during hot air and microwave drying. Journal of Food Engineering 2001, 48, 169-175.

12. Andrés, A., Bilbao, C. and Fito, P. Drying kinetics of apple cylinders under combined hot air-microwave dehydration. Journal of Food Engineering 2004, 63, 71-78

13. Beaudry, C. Evaluation of drying methods on osmotically dehydrated cranberries. Unpublished M.Sc. thesis. Montreal, QC: Department of Agricultural and Biosystems Engineering, McGill University 2001.

14. Rodriguez, A. “Comparación de métodos combinados (ósmosis directa-microondas y secado convectivo por aire caliente-microondas) para la deshidratación de frutos del bosque". PhD thesis presented to the College of Engineering of University of La Plata as requirement to obtain the academic degree of Doctor in Engineering 2014.

15. AOAC. Official methods of analysis (13th ed.). Washington, DC: Association of Official Analytical Chemists 1980.

16. Demarchi, S.M, Quintero, N.A., Concellón, A. and Giner, S. Effect of temperature on hot-air drying rate and on retention of antioxidant capacity in apple leathers. Food and Bioproducts Processing 2013, 91, 310-318. 
17. Diamante, L. M. and Munro, P. A. Mathematical modelling of the thin layer solar drying of sweet potato slices. Solar Energy 1993, 51, 271-276.

18. Doymaz, I. Air-drying characteristics of tomatoes. Journal of Food Engineering 2007, 78, 1291-1297.

19. Vargas, A., Perez, J., Zoffoli, J.P. and Perez, A. Comparación de variables de textura en la medición de firmeza de bayas de uva Thompson seedless. Ciencia e Investigación Agraria 2001, 28, 37-42.

20. Mendoza, F., Dejmek, P., Aguilera, J.M. Calibrated color measurements of agricultural foods using image analysis. Postharvest Biology and Technology 2006, 41, $285-295$.

21. Shimada, K., Fujikawa, K., Yahara, K. and Nakamura, T. Antioxidative properties of xanthin on autoxidation of soybean oil in cyclodextrin emulsion. Journal of Agricultural and Food Chemistry 1992, 40, 945-948.

22. Re, R., Pellegrinni, N., Proteggente, A., Pannala, A., Yang, M. and Rice-Evans, C. Antioxidant activity applying an improved ABTS radical cation decolorization assay. Free Radical in Biology and Medicine 1999, 26, 1231-1237.

23. Yang, C.S.T. and Atallah, W.A. Effect of on the quality of intermediate moisture Lowbush blueberries. Journal of Food Science 1985, 50, 1233-1237.

24. Beaudry, C., Raghavan, G.S.V., Ratti, C., Rennie, T.J. Effect of four drying methods on the quality of osmotically dehydrated cranberries. Drying Technology 2004, 22(3), $521-539$. 
25. Zhang, M., Tang, J., Mujumdar, A.S. and Wang, S. Trends in microwave related drying of fruits and vegetables. Trends in Food Science and Technology 2006, 17, 524534.

26. Zielinska M., Sadowski P. and Błaszczak W. Combined hot air convective drying and microwave-vacuum drying of blueberries (Vaccinium corymbosum L.): Drying kinetics and quality characteristics. Drying Technology: An International Journal 2015, DOI: $10.1080 / 07373937.2015 .1070358$

27. Venkatachalapathy, K. and Raghavan, G.S.V. Microwave drying of osmotically dehydrated blueberries. Journal of Microwave Power and Electromagnetic Energy 1998, $33,95-102$.

28. Stanisławski J. Drying of diced carrot in a combined microwave-fluidized bed dryer. Drying Technology 2005, 23, 1711-1721.

29. Mandala, I.G., Anagnostaras, E.F., Oikonomou, C.K. Influence of osmotic dehydration conditions on apple air-drying kinetics and their quality characteristics. Journal of Food Engineering 2005, 69, 307-316.

30. Therdthai, N. and Zhou, W. Characterization of microwave vacuum drying and hot air drying of mint leaves (MenthacordifoliaOpiz ex Fresen). Journal of Food Engineering $2009,91,482-489$.

31. de Bruijn, J. and Bórquez, R. Quality retention in strawberries dried by emerging dehydration methods. Food Research International 2014, 63, 42-48.

32. Alibas I. Characteristics of chard leaves during microwave, convective, and combined microwave-convective drying. Drying Technology: An International Journal 2006, 24(11), 1425-1435 
33. Changrue, V., Orsat, V. and Raghavan, G.S.V. Osmotically dehydrated microwave vacuum drying of strawberries. Journal of Food Processing and Preservation 2008, 32, 798-816.

34. Contreras, C., Martín, M.E., Martínez-Navarrete, N. and Chiralt, A. Effect of vacuum impregnation and microwave application on structural changes which occurred during air-drying of apple. LWT - Food Science and Technology 2005, 38, 471-477. 35. Cui Z., Xu S. and Sun D. Dehydration of garlic slices by combined microwavevacuum and air drying. Drying Technology: An International Journal 2003,21(7), 1173 1184.

36. Chong C.H., Law C.L., Cloke M., Hii C.L., Abdullah L.C., Daud W.R.W. Drying kinetics and product quality of dried Chempedak. Journal of Food Engineering 2008, 88, $522-527$

37. Martinez, M.V. and Whitaker, J.R. The biochemistry and control of enzymatic browning. Trends in Food Science and Technology 1995, 6, 195-200.

38. Severini, C., Baiano, A., De Pilli, T., Romaniello, R. and Derossi, A. Prevention of enzymatic browning in sliced potatoes by blanching in boiling saline solutions.

Lebensmittel-Wissenschaft und -Technologies 2003, 36, 657-665.

39. Münsell, A.H., A. Color Notation. Editorial G. H. Ellis Co., 1905, Boston - E.E.U.U. 40. Moreno, M., Víctor, M., Documento Psicología del color y la forma. Universidad de Londres, 2005, Querétaro - México.

Tabtiang, S., Prachayawarakon, S. and Soponronnarit, S. Effects of osmotic treatment 
and superheated steam puffing temperature on drying characteristics and texture properties of banana slice. Drying Technology 2012, 30(1), 20-28.

41. Zou, K., Teng, J., Huang, L., Dai, X. and Wei, B. Effect of osmotic pretreatment on quality of mango chips by explosion puffing drying. LWT-Food Science and Technology $2013,51,253-259$.

42. Nsonzi F. and Ramaswamy H.S. Quality evaluation of osmo convective dried blueberries. Drying Technology: An International Journal 1998, 16 (3-5), 705-723 43. Rózek, A., García-Perez, J.V., López, F., Güell, C. and Ferrando, M. Infusion of grape phenolic into fruits and vegetables by osmotic treatment: Phenolic stability during air drying. Journal of Food Engineering 2010, 99, 142-150.

44. Garau, M.C., Simal, S., Roselló, C. and Femenia, A. Effect of air-drying temperature on physic-chemical properties of dietary fiber and antioxidant capacity of orange (Citrus aurantium v. Canoneta) by-products. Food Chemistry 2007, 104, 1014-1024.

45. Ghamena, N., Mihoubib, D., Kechaoua, N. and Mihoubic, N.B. Microwave dehydration of three citrus peel cultivars: Effect on water and oil retention capacities, color, shrinkage and total phenols content. Industrial Crops and Products 2012, 40, 167177.

46. Kaymak-Ertekin, F. Drying and rehydrating kinetics of green and red peppers. Journal of Food Science 2002, 67(1), 168-175.

47. Drouzas, A.E., Schubert, H. Microwave application in vacuum drying of fruits. Journal Food Engineering 1996, 28, 203-209.

48. Krokida, M.K. and Maroulis, Z.B. Effect of microwave drying on some quality properties of dehydrated products. Drying Technology 1999 , 17, 449-466 
49. Miranda, M., Vega-Gálvez, A., García, P., Di Scala, K., Shic, J., Xuec, S., Uribe, E. Effect of temperature on structural properties of Aloe vera (Aloe barbadensis Miller) gel and Weibull distribution for modelling drying process. Food and Bioproducts Processing2010, 88 (2-3), 138-144.

50. Taiwo, K.A., Angersbach, A. and Knorr, D. Rehydration studies on pretreated and osmotically dehydrated apple slices. Journal of Food Science 2002, 67, 842-847.

51. Stojanovic, J., Silva J.L. Influence of osmoconcentration, continuous high frequency ultrasound and dehydration on properties and microstructure of Rabbiteye blueberries. Drying Technology 2006, 24(2), 165-171. 
Figure 1. a) Kinetics of combined processes (OD-MWD and HAD-MWD) and the control drying (HAD) of blueberries in function of time; b) Kinetic curves of MW drying in blueberries pretreated with OD; c) Kinetic curves of microwave drying in blueberries pretreated with HAD

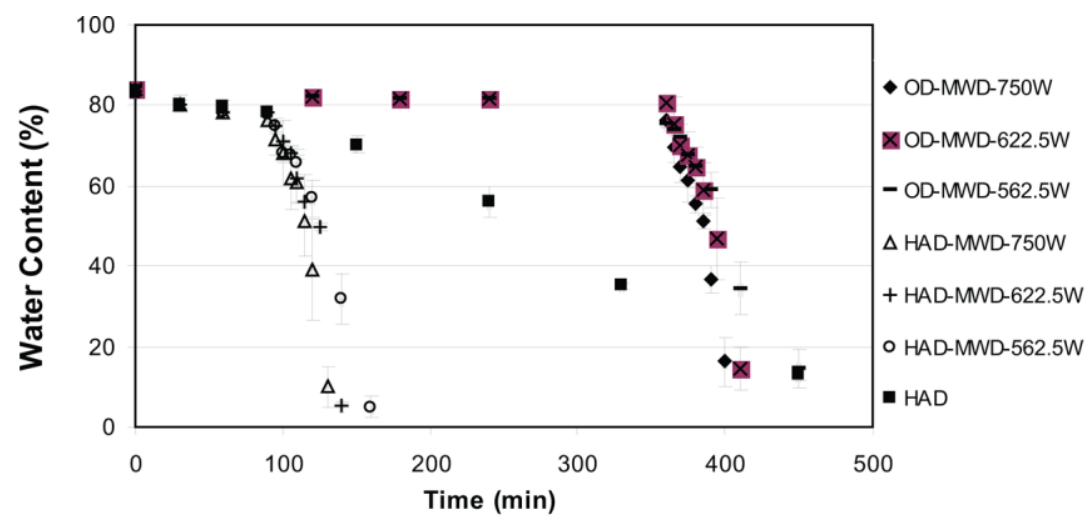

(a)

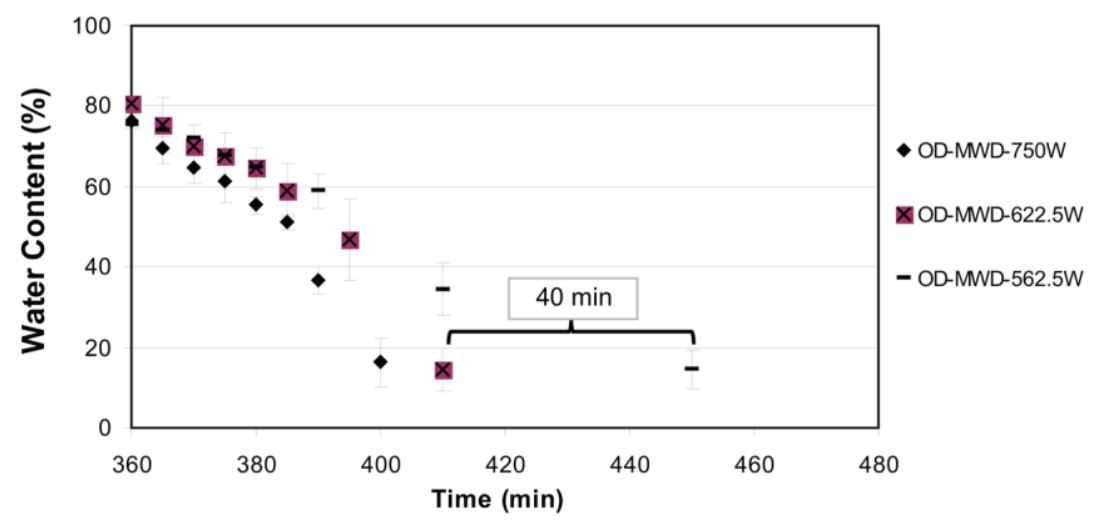

(b)

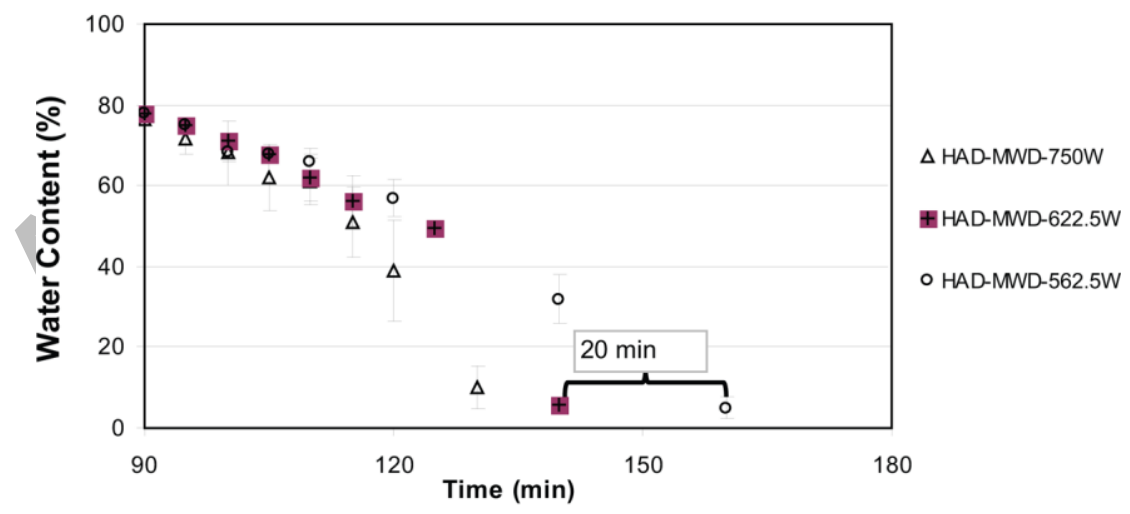

(c) 
Figure 2. Kinetic curvesthe water activity during blueberries drying

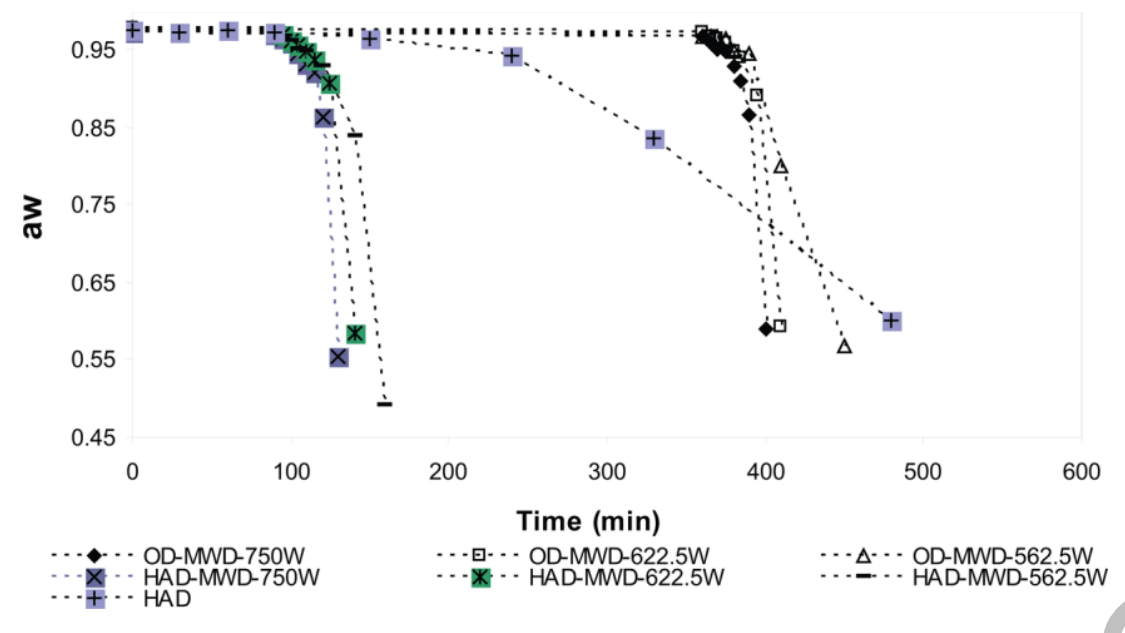


Figure 3. Behavior of the drying rates of the combined processes (HAD-MWD and ODMWD) and control drying (HAD) of blueberries in function of MR

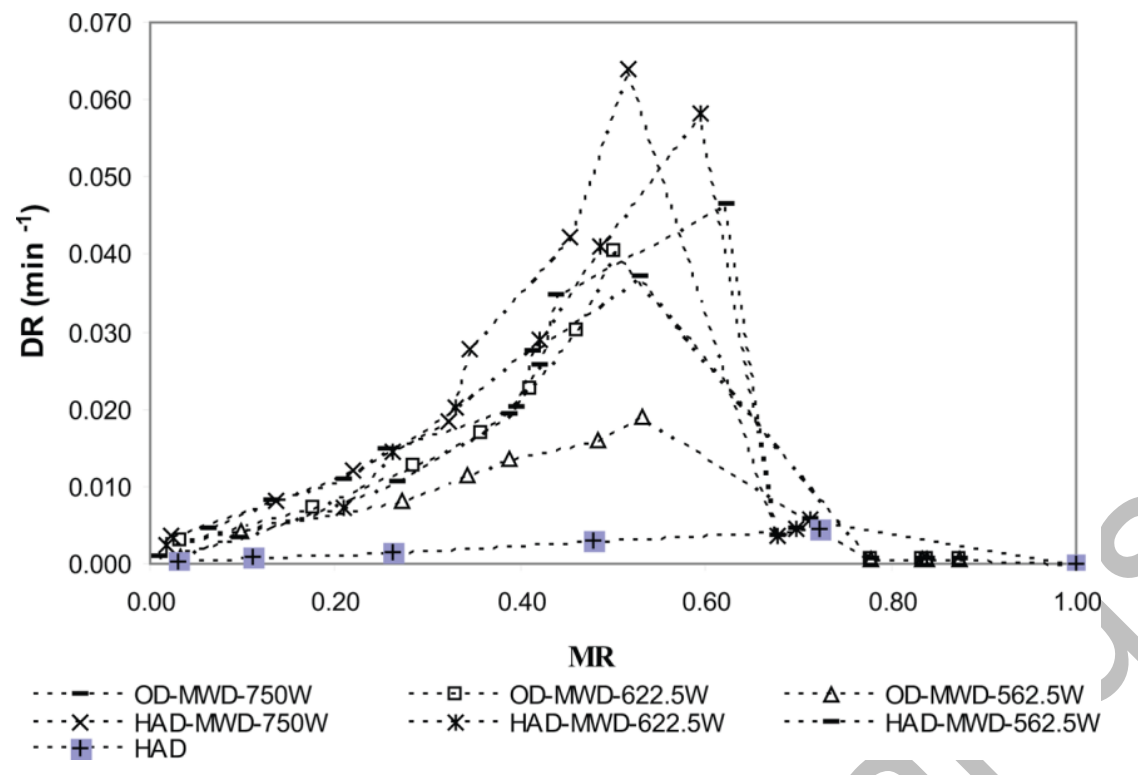


Figure 4. Mechanical responses a) Firmness and b) Stiffness of dried blueberries obtained at the end of the different combined processes (OD-MWD and HAD-MWD) and control drying (HAD). Bars with different letters indicate significant differences according to a Tuckey test $(\mathrm{p}<0.05)$

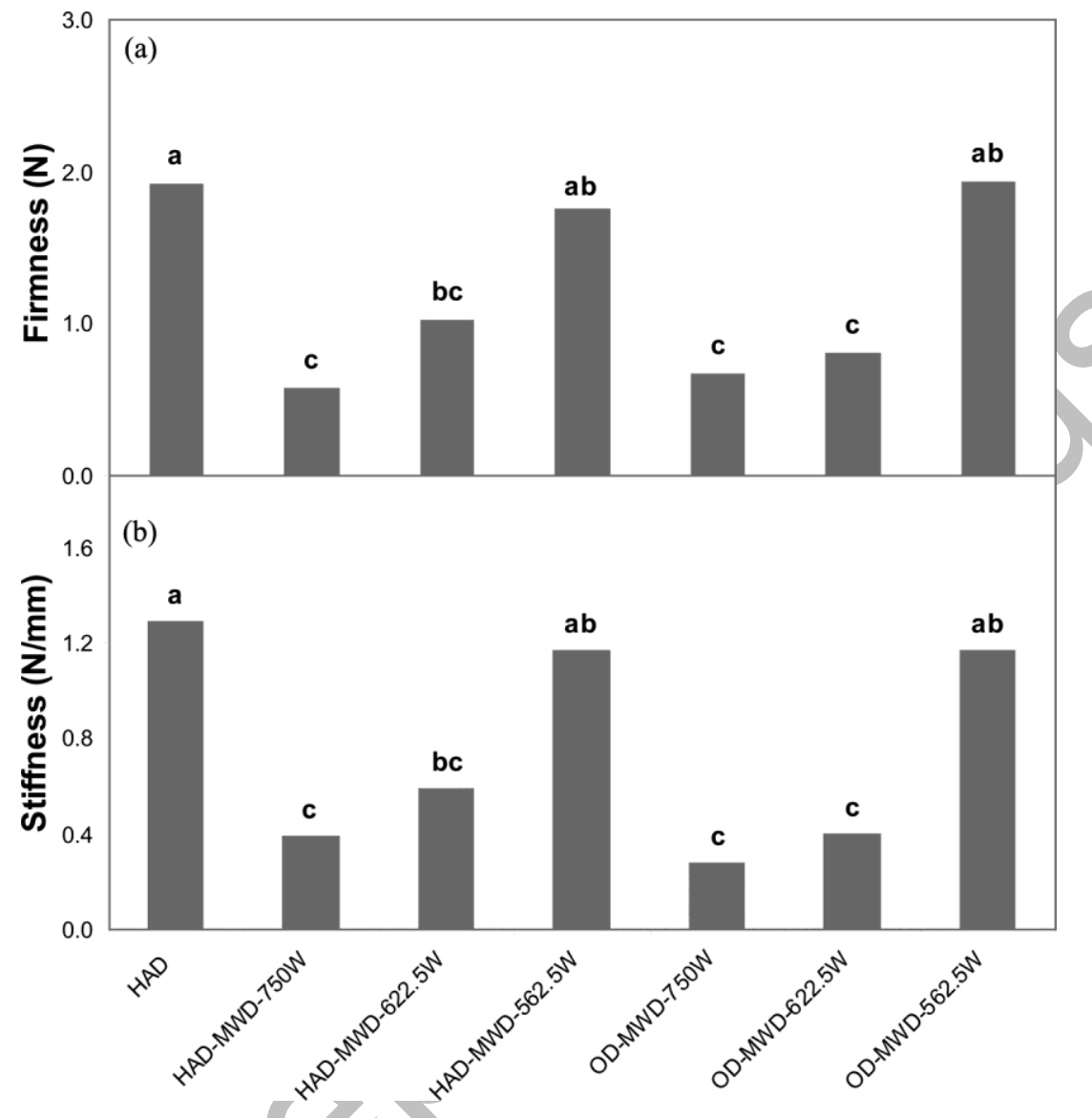


Figure 5. Color parameters a) $h$, b) a* and c) L* of natural fresh blueberries, blueberries treated with alkali emulsion of ethyl oleate (AEEO) and at the end of the combined processes (OD-MWD and HAD-MWD) and control drying (HAD). Bars with different letters indicate significant differences according to a Tuckey test $(\mathrm{p}<0.05)$.

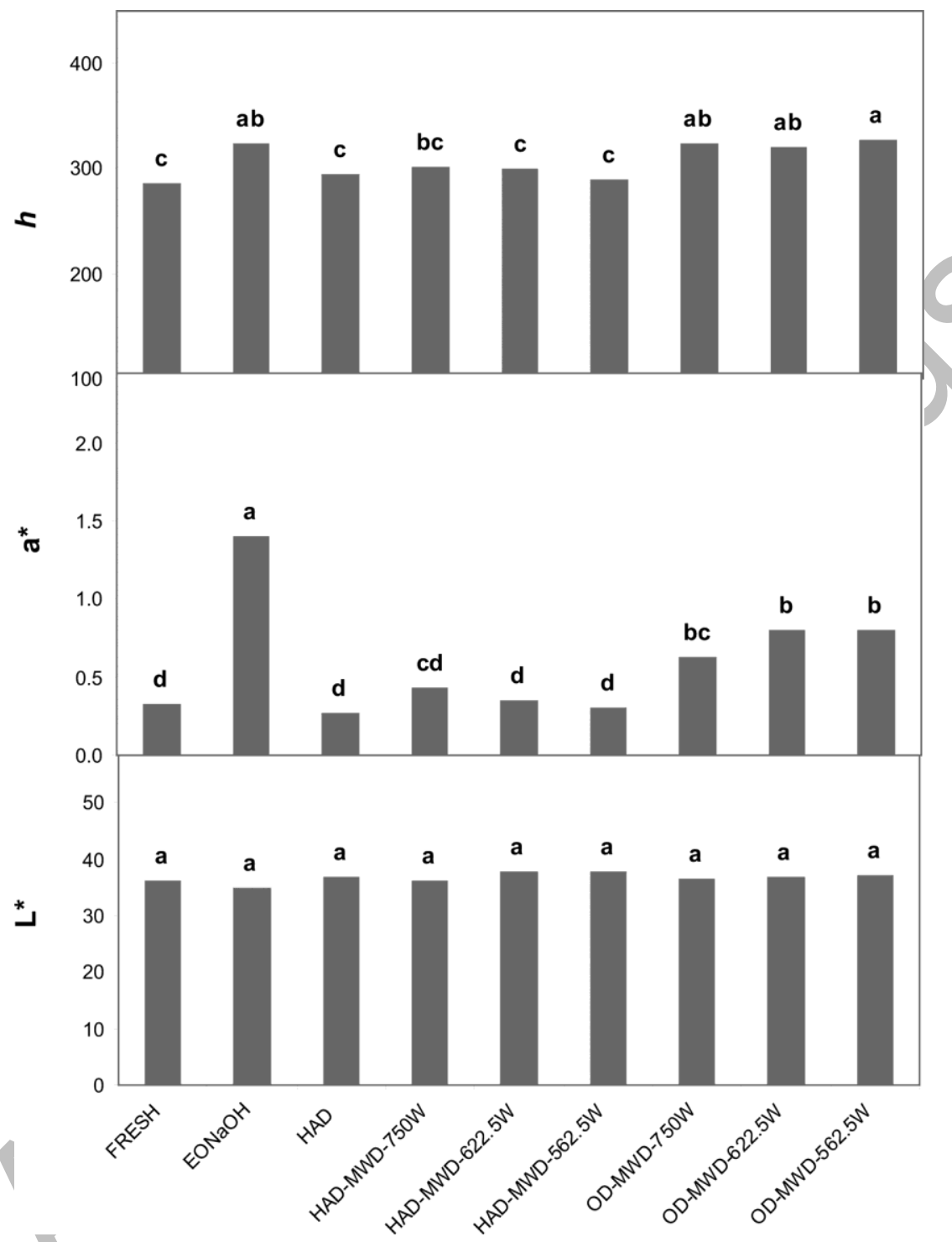


Figure 6. Effect of the different combined drying and the control drying over antioxidant capacity of dried blueberries samples a) Antioxidant Retention (\%) by $1 / \mathrm{EC}_{50}$ and b) Antioxidant Retention (\%) by ABTS. Bars with different letters indicate significant differences according to a Tuckey test $(\mathrm{p}<0.05)$ analysis.

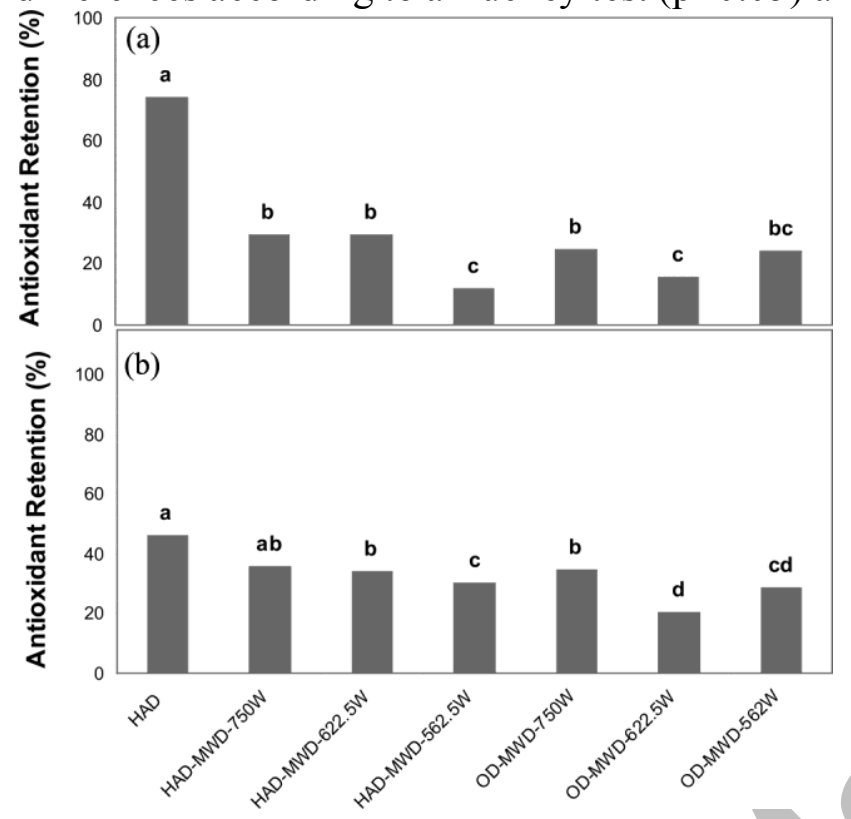


Figure 7. a) Rehydration capacity of dried blueberries, b) Firmness of rehydrated blueberries and c) Stiffness of rehydrated blueberries. Bars with different letters indicate significant differences according to a Tuckey test $(\mathrm{p}<0.05)$.
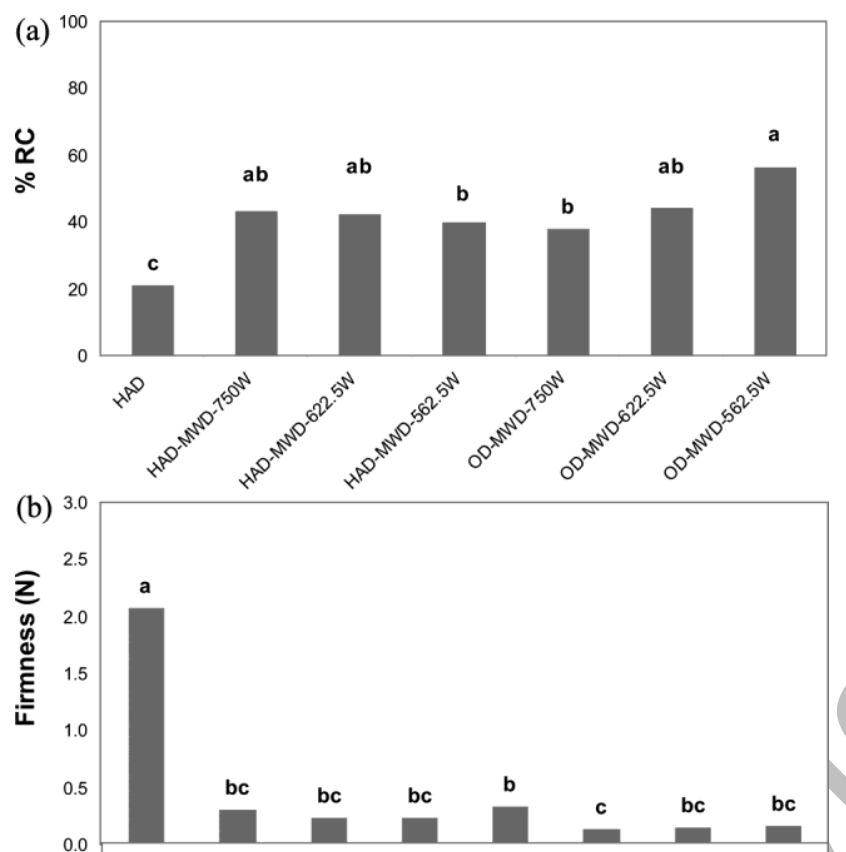

(c)

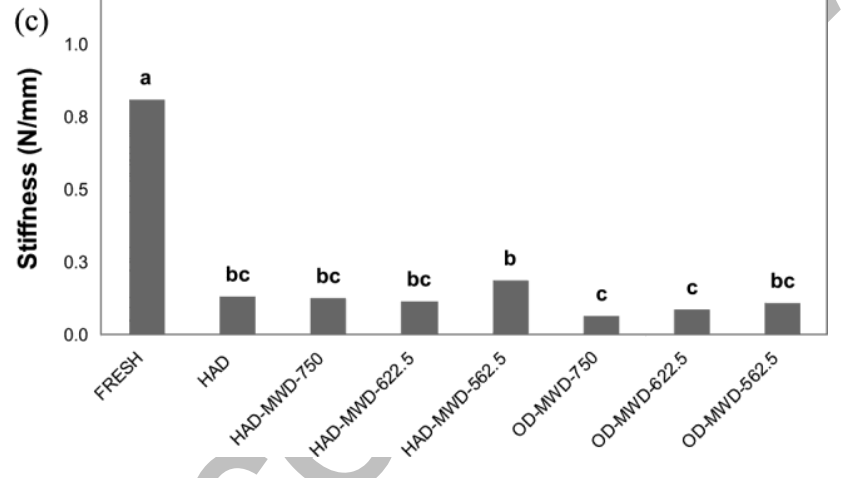

